\title{
The Effects of Physical Activity on Learning Behaviors in Elementary School Children: a Randomized Controlled Trial
}

\author{
Susan P. Harvey ${ }^{1}$ - Kate Lambourne ${ }^{2}$ - Jerry L. Greene ${ }^{1} \cdot$ Cheryl A. Gibson $^{3}$. \\ Jaehoon Lee ${ }^{4} \cdot$ Joseph E. Donnelly ${ }^{5}$
}

Published online: 17 July 2017

(C) The Author(s) 2017. This article is an open access publication

\begin{abstract}
Research in education and developmental psychology indicates that behavioral engagement in learning is a critical predictor of children's academic success. In an effort to improve academic achievement, school administrators are continually in search of methods to increase behavioral engagement. Previous research has indicated that classroombased physical activity (PA) lessons have a positive impact on academic achievement. However, little research has been done in assessing the impact of such interventions on the behavioral engagement of students with learning behavior difficulties. This study assesses the impact of classroom-based PA on teacher-rated classroom behaviors of students with identified learning behavior difficulties. Two schools (one intervention, one control) participating in a larger, clusterrandomized trial provided scores on a teacher-administered classroom behavior scale. This scale was used to collect
\end{abstract}

Susan P. Harvey

suharvey@ku.edu

Kate Lambourne

katel@ku.edu

Jerry L. Greene

jlg@ku.edu

Cheryl A. Gibson

cgibson@kumc.edu

Jaehoon Lee

jaehoon.lee@ttu.edu

Joseph E. Donnelly

jdonnelly@ku.edu information on 15 characteristics identified as being essential to behavioral engagement. Participants included male and female students in second and third grade classrooms who were identified by their classroom teacher and school counselor as having difficulties with learning behaviors. Mixed linear modeling for repeated measures was used to examine the changes over time in the classroom behavior scores. The intervention group showed significant improvement over time in classroom behavior while the control group showed no change or a slight degradation over time (i.e., group $\times$ time interaction, $F[2132]=4.52, p=0.01)$. Schools must meet the diverse needs of students today, including those who exhibit less than optimal learning behaviors. Combined with the evidence that PA is linked to several health and cognitivebehavior benefits, providing classroom-based PA that is incorporated within the curriculum provides common ground for

Department of Health, Sport, and Exercise Sciences, University of Kansas, 1301 Sunnyside Avenue, Lawrence, KS 66045, USA

2 ICF International, 9300 Lee Highway, Fairfax, VA 22031, USA

3 Department of Internal Medicine, University of Kansas Medical Center, 3901 Rainbow Blvd., Kansas City, KS 66160, USA

4 Educational Psychology and Leadership, Texas Tech University, 2500 Broadway Street, Lubbock, TX 79409, USA

5 Energy Balance Laboratory, Center for Physical Activity and Weight Management, University of Kansas, 1301 Sunnyside Ave., Lawrence, KS 66045, USA 
all students to participate. It is a potential solution to increasing behavioral engagement, and in turn stimulating and enhancing learning.

Keywords Learner behaviors · Behavioral engagement . Physical activity

\section{Background}

Research in education and developmental psychology indicates that behavioral engagement in learning is a critical predictor of children's academic success (Brophy and Good 1986; Fredricks et al. 2004; Greenwood et al. 2002). Behavioral engagement is a multifaceted concept and can be defined as a student's active involvement in classroom tasks, including complying with classroom rules and routines, absence of disruptive behaviors (Finn 1993; Finn et al. 1995; Finn 1997), effort, persistence, attention, and concentration on tasks, and asking questions and contributing to class discussions (Finn et al. 1995; Birch and Ladd 1997; Skinner and Belmont 1993). Much research has focused on classroom-based interventions to improve behavioral engagement, as it has become a national priority for schools to demonstrate academic success.

Just as behavioral engagement is positively correlated with academic success, results of classroom-based physical activity (PA) interventions have also indicated increases in academic achievement (Centers for Disease Control and Prevention 2010). Physical activity breaks have been shown to improve some of the behavioral engagement components necessary for learning, including increased time on task (Barros et al. 2009; Gabbard and Barton 1979; Jarrett et al. 1998; Mahar et al. 2006), reduced fidgeting (Jarrett et al. 1998), and better concentration (McNaughten and Gabbard 1993).

Schools seeking the magic bullet to increase student engagement and enhance academic achievement face multiple barriers in finding a common solution. Among one of the main challenges is meeting the needs of diverse students or those who are identified as at risk for failure or dropout due to concerns in their level of engagement within the classroom. Approximately 50.1 million students attend public elementary and secondary schools, and an additional 4.9 million students attend private schools in the USA (United States Department of Education, Institute of Education Sciences, National Center for Education Statistics Common Core of Data (CCD) 2016). Among these children, it is estimated that $13-20 \%$ of them (up to 1 out of 5) experience a mental disorder in a given year (Perou et al. 2013). Mental disorders can be diagnosed and begin in childhood and include a wide range of disorders including attentiondeficithyperactivity disorder (ADHD), Tourette syndrome, behavior disorders, mood and anxiety disorders, and autism spectrum disorders (Perou et al. 2013). Students with mental disorders can especially struggle with behavioral engagement, resulting in poor academic achievement, high rates of absenteeism, and school dropout
(Finn 1997; Croninger and Lee 2001; DuPaul et al. 2004; Finn 1989). Though research is limited in this area, a few studies have indicated that students who struggle with such behaviors may benefit from engaging in PA by increasing time-on-task behaviors (Mahar et al. 2006), reducing aggressive behaviors (Gabler-Halle et al. 1993), unproductive and disruptive behaviors, and improving attention span (McKimsey and Favell 1988).

Critics of school-based PA, however, argue that classroombased PA breaks may further disrupt the classroom environment and compete with curriculum demands (Naylor et al. 2006). Research suggesting that PA may improve behavioral engagement in the classroom challenges the notion that increasing time spent on academics is the most effective method for improving standardized test scores. Consequently, the pressure on school administrators and teachers to increase academic achievement often leads to the reduction or elimination of opportunities for PA (Mahar et al. 2006).

Recognizing that schools play an essential role in promoting student health, Congress passed the Child Nutrition and Special Supplemental Nutrition Program for Women, Infants, and Children (WIC) Reauthorization Act in 2004 (US Department of Health and Human Services 2006). This law mandates that schools with a federally funded school meal program implement wellness policies that address PA and nutrition. In 2013, the American Alliance for Health, Physical Education, Recreation, and Dance released a position statement recommending that all schools implement a comprehensive school physical activity program (CSPAP) (Elliot et al. 2013). The position statement supports recommendations by the Department of Health and Human Services and other leading public health, medical and educational organizations, and researchers that children and adolescents should be involved in moderate-to-vigorous PA at least $60 \mathrm{~min}$ per day (US Department of Health and Human Services 2008). The statement goes on to further emphasize the school's role in meeting these national recommendations through highquality physical education programs, PA during the school day, and PA before and after school by mobilizing efforts from school staff, family, and the community. However, it is recognized that even with high-quality physical education classes, students need additional opportunities for PA to meet these recommendations, and that activity breaks throughout the day are one way to help meet these guidelines, while contributing to improvements in cognitive skills, concentration, and classroom behavior.

Despite these guidelines, students spend the majority of their time in school in sedentary activities, occupying between 6 and $8 \mathrm{~h}$ per day in academic instruction (Donnelly and Lambourne 2011). Adding to this, research has demonstrated that children spend less than half their time in physical education classes engaged in moderate-to-vigorous PA (Levin et al. 2001). Furthermore, even with the Child Nutrition and Special Supplemental Nutrition Program for WIC Reauthorization 
Table 1 Sample physically active classroom lessons

\begin{tabular}{|c|c|c|}
\hline Subject & Subject topic & Physical activity \\
\hline Math & $\begin{array}{l}\text { Field of vision is } 180^{\circ} \text {. Students } \\
\text { stand and begin walking in place. }\end{array}$ & $\begin{array}{l}\text { If } 90^{\circ} \text { is } 50 \% \text { of the field of vision and one } \\
\text { kangaroo jump equals } 10 \% \text {, how many } \\
\text { kangaroo jumps would you perform to } \\
\text { equal } 50 \% \text { ? Students will do five } \\
\text { kangaroo jumps and continue } \\
\text { walking in place. }\end{array}$ \\
\hline Spelling & $\begin{array}{l}\text { Seven continents on Earth. Students } \\
\text { stand and begin marching in place. }\end{array}$ & $\begin{array}{l}\text { All continents are listed on a whiteboard. } \\
\text { Students will spell each continent starting } \\
\text { with the smallest to the largest. Students } \\
\text { will hop off of both feet as they say each } \\
\text { letter for each continent. }\end{array}$ \\
\hline $\begin{array}{l}\text { Language } \\
\text { Arts }\end{array}$ & $\begin{array}{l}\text { Homophones. Words will be listed on a } \\
\text { whiteboard. Students stand begin } \\
\text { a brisk walk in place. }\end{array}$ & $\begin{array}{l}\text { As the teacher points to a word and gives it a } \\
\text { meaning, students will do movement to } \\
\text { show they understand, for example, peer } \\
\text { (jog for } 30 \text { s) and pier (jump } 10 \text { times). } \\
\text { Continue walking until next } \\
\text { homophone is given. }\end{array}$ \\
\hline Science & $\begin{array}{l}\text { Force and speed. Students start with a } \\
\text { sitting position that is easy for them } \\
\text { to stand and sit in a safe manner. }\end{array}$ & $\begin{array}{l}\text { On cue, students "slowly" raise from a sitting } \\
\text { position to a standing position. Now, slowly } \\
\text { lower the body back to a sitting position. Do } \\
\text { this five times. Now raise the body to a standing } \\
\text { position as "fast" as you can. Lower the body } \\
\text { to the chair as fast as you can. Do this three } \\
\text { times. Stand and start walking in place as we } \\
\text { discuss the differences in force and speed. }\end{array}$ \\
\hline
\end{tabular}

With all physical activity, safety is discussed with the students. The curriculum content and the physical activity will vary among grade levels. The above sample activities are directly related to the state's core curriculum and serve as examples of how PA can easily be part of the classroom learning process.
Act, schools have for the most part focused their attention on improving the nutritional environment, all but ignoring policies to engage students and staff in PA (Kibbe et al. 2011).

While some studies have conducted observational research of how specific behavioral components, such as time on task, are affected by classroom PA breaks, to date, no known published study has used a comprehensive behavioral engagement scale to examine the impact of daily classroom-based PA on behavior with students who have previously been identified as struggling with learning behaviors. Thus, the purpose of this study was to compare learning behavior components between students who received physically active classroombased academic lessons to those children who received lessons delivered in the traditional non-active classroom.

\section{Methods}

\section{Study Design}

This study was part of a larger 3-year cluster randomized, controlled trial of 17 elementary schools to determine if classroom-based PA lessons delivered by classroom teachers could enhance academic achievement significantly. The design and methods of the large cluster-randomized trial have been previously published (Donnelly et al. 2013). Briefly, 17 elementary schools were cluster randomized to intervention (A + PAAC, 9 schools) or control (8 schools) for a 3-year trial. Classroom teachers were trained to deliver academic instruction through moderate-to-vigorous PA with a target of $100 \mathrm{~min}$ of A + PAAC activities per week. The PA lessons were designed to be used in a variety of academic disciplines including math, language arts, geography, history, spelling, science, and health, and were directly related to the state's core curriculum. A sample of activities are included in Table 1. The primary outcome measure was academic achievement measured by the Weschler Individual Achievement Test-III. The ancillary learning behavior study enrolled a sample of students

Table 2 Sample characteristics

\begin{tabular}{llll}
\hline & Intervention & Control & Total \\
\hline Male & & & \\
$\quad$ Second grade & 17 & 5 & 22 \\
$\quad$ Third grade & 4 & 5 & 9 \\
Female & & & \\
$\quad$ Second grade & 11 & 10 & 21 \\
$\quad$ Third grade & 11 & 5 & 16 \\
Total & 43 & 25 & 68 \\
\hline
\end{tabular}


from two schools within the same district, one delivering A + PAAC academic lessons and one control school delivering lessons in a usual manner. Levels of behavioral engagement were assessed among students identified as having difficulties with learning behaviors.

\section{Participants}

Participants included male and female students in second and third grade general education classrooms at two urban public schools in northeast Kansas. Racial/ethnicity information was not collected; however, both school buildings report white students as their primary demographic makeup (>70\%). Parents of students who were identified by their classroom teacher and school counselor as having difficulties with learning behaviors or were on individual education plans (IEPs) targeting behavioral goals were approached for this study. Students returning signed parental informed consent forms were assessed on 15 outcome variables related to behavioral engagement. Table 2 provides a summary of the sample characteristics. This study was approved by the institutional review boards at the University of Kansas and the school district.

\section{Instruments}

A learning behavior scale measuring general learner outcomes (GLOs) and developed by the Hawaii Department of Education (Education HD of General Learner Outcome Scale 2016) was utilized for this study. The behavior scale was adopted by the district for use by classroom teachers and had been utilized for several years. The scale collected information on 15 observable characteristics identified in the literature as being essential to behavioral engagement, such as effort, work habits, and cooperation skills, and are evaluated separately from academic performance. Students were rated on behaviors using four criteria: (1) "E," excels: consistently goes beyond learner behavior expectations. Evidence of most recent work demonstrates that the learner behavior goals are fully and consistently met; (2) "S," successfully meets: meets learner behavior expectations. Evidence of most recent work demonstrates that the learner behavior goals are fully and consistently met; (3) "M," making progress: partially meets learner behavior expectations. Evidence of most recent work demonstrates that more than half the learner behavior goals are fully and consistently met; and (4) "T," targeted: targeted for growth in order to meet learner behavior expectations. Evidence of most recent work demonstrates that only a few of the learner behavior goals are met or partially met. Though the scale had been adopted for use from a separate district, reliability and validity properties of the scale are unknown. Table 3 shows the scale used for this study.

\section{Procedures}

In accordance with district policies, each school year teachers and counselors worked closely together to identify and monitor students with learning behavior difficulties. Counselors trained teachers in how to complete the scale, and prior to completion, teachers and the school counselor would meet to again discuss completion of the scale to ensure accuracy. Once the scale was completed on each identified student, the teacher and counselor would meet again to debrief on the results of the scale for each student and identify interventions to increase engagement of students who were particularly struggling. Accuracy in completion of the scale was critical, as the results of the scale followed each identified student throughout their school career in order to monitor progress, address concerns, and develop interventions to attend to problematic behaviors. The scale was completed on each identified student at three time points across the school year, usually near the beginning of the trimester (September, December, March).

\section{Data Analysis}

The participants' demographics and classroom behavior scores were summarized by descriptive statistics and bivariate tests. Then, mixed linear modeling for repeated measures was used to examine the changes over time in the scores for the intervention and control groups. Specifically, mixed models estimated the effects of time, group, and time-by-group interaction accounting for the participants' gender (Hox 1995; Maas and Hox 2004; Maas and Hox 2005). Statistical significance was determined at the 0.05 alpha level, and all analyses were conducted using SAS 9.4 (SAS Institute 2002-2012).

\section{Results}

Students in second and third grade classrooms identified by their teacher and school counselor as having learning behavior difficulties were tracked with the behavioral engagement scale at three time points over the course of the school year. Within the intervention school, 21 male and 22 female $(n=43)$ students were measured. In the comparison school, 10 male and 15 female $(n=25)$ students were assessed. Distributions of grade $\left(\chi^{2}[1]=0.18, p=0.67\right.$, Cramer's $\left.V=0.05\right)$ and gender $\left(\chi^{2}[1]=0.50, p=0.48, V=0.09\right)$ did not differ between groups.

Multivariate assumptions were checked prior to analyses. Standardized skewness scores and the Shapiro-Wilk test results confirmed normality of the overall classroom behavior score at each time point within each group. The Levene's test results also indicated homogenous variances of the overall score between groups. Table 4 provides results for the intervention group for each of the behavioral engagement 
Table 3 Learner Behaviors Scale

\begin{tabular}{llll}
\hline Learner behaviors & $\begin{array}{l}\text { Trimester 1, } \\
\text { September } \\
\text { (baseline) }\end{array}$ & $\begin{array}{l}\text { Trimester 2, } \\
\text { December }\end{array}$ \\
\hline
\end{tabular}

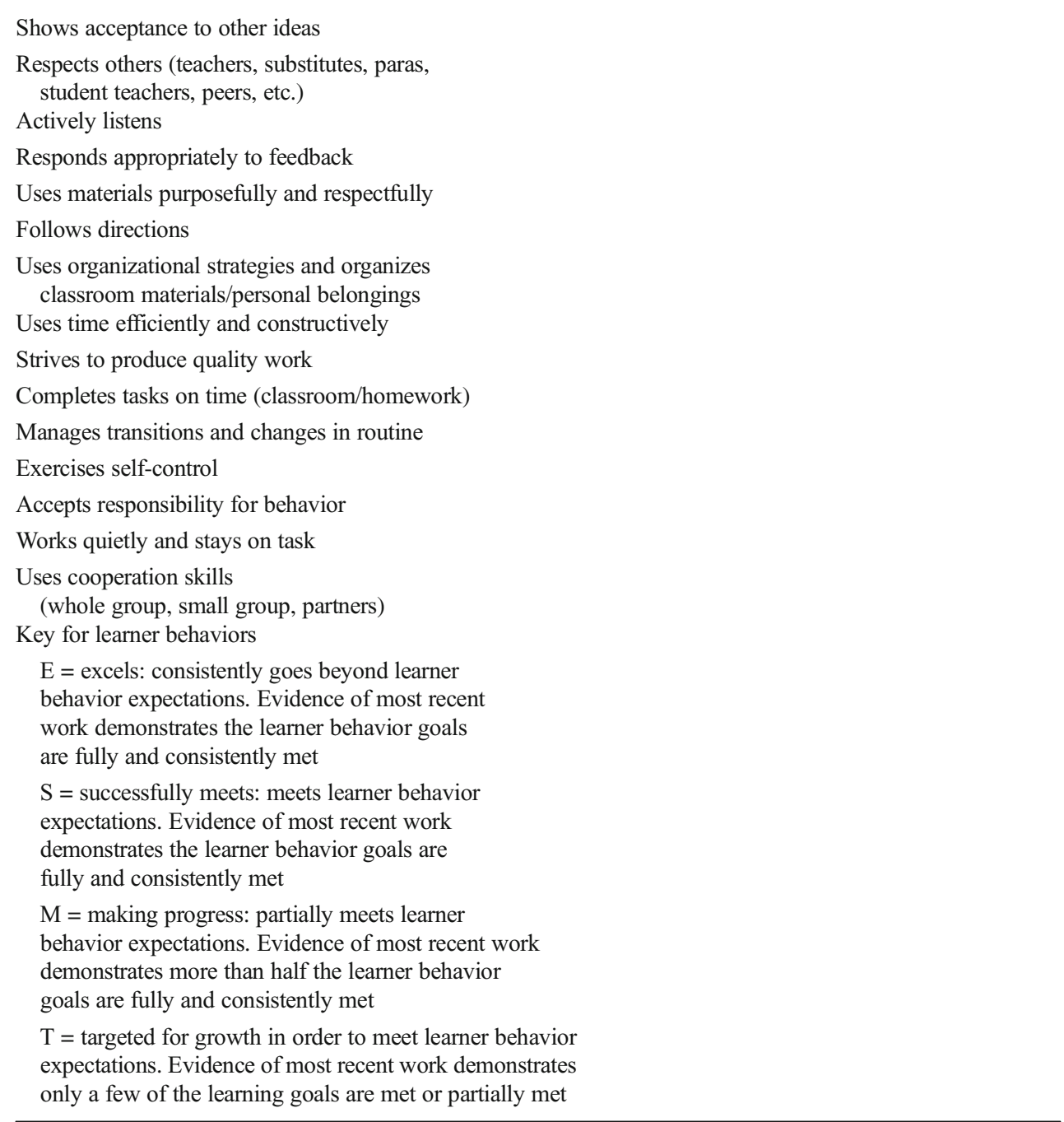

components across time. Table 5 shows the mean scores for both groups across time. Results of the mixed linear modeling for repeated measures indicated that the intervention group of students receiving the classroom-based physically active lessons showed significant improvements over time in the overall behavior engagement score, i.e., slow then steep increases in the score $(95 \%$ CI for change from T1 to T2 $=[0.00,0.13]$, Cohen's $d=0.43,95 \%$ CI for change from T2 to T3 $=[0.06$, $0.19], d=0.81 ; F(2,84)=17.29, p<0.0001)$. Results for the control group showed no change or a slight degradation over time $(95 \%$ CI for change from $\mathrm{T} 1$ to $\mathrm{T} 2=[-0.09,0.08]$, $d=0.03,95 \%$ CI for change from T2 to T3 $=[-0.11,0.06]$, $d=0.16 ; F[2,48]=0.26, p=0.77)$. This pattern of changes was also confirmed by a significant group-by-time interaction in a subsequent mixed modeling analysis $(F(2,132)=4.52$, $p<0.05)$. Figure 1 illustrates this group-by-time interaction.

\section{Discussion}

School teachers and administrators are increasingly concerned with providing evidence of academic achievement through standardized test scores. In order to increase these scores, schools often find themselves restricting or eliminating time spent in PA in order to dedicate more time spent in the classroom. These actions, however, do not support a healthy school environment as mandated by the Child Nutrition and Special Supplemental Program for Women, Infants, and Children in which policies addressing PA be implemented, enforced, and evaluated.

Additionally, school districts are struggling to meet the diverse needs of students today. Homelessness, hunger, mood disorders, and ADHD are just a few examples of how a 
Table 4 Intervention student mean scores and time effect

\begin{tabular}{|c|c|c|c|c|c|c|c|c|}
\hline & \multicolumn{2}{|l|}{$\mathrm{T} 1$} & \multicolumn{2}{|l|}{$\mathrm{T} 2$} & \multicolumn{2}{|l|}{$\mathrm{T} 3$} & \multirow[b]{2}{*}{$F$} & \multirow[b]{2}{*}{$p$} \\
\hline & $M$ & $S D$ & $M$ & $S D$ & $M$ & $S D$ & & \\
\hline \multicolumn{9}{|l|}{ Male $(n=21)$} \\
\hline Shows acceptance of other ideas & 1.95 & 0.59 & 2.00 & 0.45 & 2.05 & 0.50 & 1.54 & 0.227 \\
\hline Respects others & 1.90 & 0.70 & 2.14 & 0.73 & 2.14 & 0.73 & 4.95 & 0.012 \\
\hline Actively listens & 1.90 & 0.62 & 2.10 & 0.70 & 2.05 & 0.74 & 3.66 & 0.035 \\
\hline Responds appropriately to feedback & 1.76 & 0.62 & 2.00 & 0.63 & 1.95 & 0.67 & 3.33 & 0.046 \\
\hline Uses materials purposefully and respectfully & 2.10 & 0.54 & 2.05 & 0.74 & 2.14 & 0.57 & 1.00 & 0.377 \\
\hline Follows directions & 1.67 & 0.58 & 1.71 & 0.78 & 1.86 & 0.65 & 1.48 & 0.240 \\
\hline Uses organizational strategies & 2.05 & 0.59 & 1.95 & 0.80 & 2.05 & 0.67 & 0.49 & 0.618 \\
\hline Uses time efficiently & 1.57 & 0.60 & 1.81 & 0.75 & 2.00 & 0.63 & 7.18 & 0.002 \\
\hline Strives to produce quality work & 1.81 & 0.51 & 1.81 & 0.51 & 2.00 & 0.71 & 1.65 & 0.205 \\
\hline Completes tasks on time & 1.86 & 0.36 & 2.00 & 0.63 & 2.10 & 0.54 & 1.99 & 0.150 \\
\hline Manages transitions and changes in routine & 1.86 & 0.48 & 1.86 & 0.65 & 2.05 & 0.38 & 2.91 & 0.066 \\
\hline Exercises self-control & 1.57 & 0.68 & 1.52 & 0.75 & 1.62 & 0.67 & 0.49 & 0.618 \\
\hline Accepts responsibility for behavior & 1.90 & 0.70 & 1.90 & 0.70 & 2.05 & 0.59 & 0.40 & 0.104 \\
\hline Works quietly and stays on task & 1.67 & 0.58 & 1.62 & 0.67 & 1.71 & 0.56 & 0.36 & 0.697 \\
\hline Uses cooperation skills & 1.81 & 0.51 & 1.81 & 0.60 & 2.05 & 0.74 & 4.10 & 0.024 \\
\hline Mean score & 1.83 & 0.39 & 1.89 & 0.47 & 1.99 & 0.46 & 6.90 & 0.003 \\
\hline \multicolumn{9}{|l|}{ Female $(n=22)$} \\
\hline Shows acceptance of other ideas & 2.09 & 0.29 & 2.14 & 0.35 & 2.23 & 0.43 & 2.49 & 0.095 \\
\hline Respects others & 2.09 & 0.29 & 2.18 & 0.39 & 2.27 & 0.46 & 3.32 & 0.046 \\
\hline Actively listens & 2.00 & 0.44 & 2.09 & 0.68 & 2.09 & 0.53 & 0.56 & 0.575 \\
\hline Responds appropriately to feedback & 1.95 & 0.21 & 2.05 & 0.38 & 2.05 & 0.38 & 2.10 & 0.135 \\
\hline Uses materials purposefully and respectfully & 2.00 & 0.44 & 2.05 & 0.72 & 2.27 & 0.63 & 4.49 & 0.017 \\
\hline Follows directions & 2.00 & 0.31 & 2.27 & 0.55 & 2.36 & 0.58 & 8.81 & 0.001 \\
\hline Uses organizational strategies & 2.09 & 0.43 & 2.23 & 0.61 & 2.23 & 0.69 & 0.90 & 0.416 \\
\hline Uses time efficiently & 2.05 & 0.38 & 2.00 & 0.62 & 2.23 & 0.61 & 3.32 & 0.046 \\
\hline Strives to produce quality work & 2.00 & 0.31 & 1.95 & 0.49 & 2.27 & 0.46 & 6.79 & 0.003 \\
\hline Completes tasks on time & 1.91 & 0.29 & 2.09 & 0.68 & 2.14 & 0.64 & 2.49 & 0.095 \\
\hline Manages transitions and changes in routine & 2.09 & 0.29 & 2.05 & 0.49 & 2.32 & 0.57 & 4.49 & 0.017 \\
\hline Exercises self-control & 2.00 & 0.31 & 2.14 & 0.47 & 2.32 & 0.57 & 4.25 & 0.021 \\
\hline Accepts responsibility for behavior & 2.09 & 0.29 & 2.09 & 0.29 & 2.18 & 0.39 & 2.10 & 0.135 \\
\hline Works quietly and stays on task & 1.91 & 0.53 & 1.86 & 0.56 & 2.14 & 0.56 & 6.45 & 0.004 \\
\hline Uses cooperation skills & 2.00 & 0.00 & 2.09 & 0.29 & 2.32 & 0.48 & 7.12 & 0.002 \\
\hline Mean score & 2.02 & 0.24 & 2.08 & 0.36 & 2.23 & 0.41 & 10.15 & 0.001 \\
\hline \multicolumn{9}{|l|}{ Combined $(n=43)$} \\
\hline Shows acceptance of other ideas & 2.02 & 0.46 & 2.07 & 0.40 & 2.14 & 0.47 & 4.07 & 0.021 \\
\hline Respects others & 2.00 & 0.53 & 2.16 & 0.57 & 2.21 & 0.60 & 7.75 & 0.001 \\
\hline Actively listens & 1.95 & 0.53 & 2.09 & 0.68 & 2.07 & 0.63 & 2.95 & 0.058 \\
\hline Responds appropriately to feedback & 1.86 & 0.47 & 2.02 & 0.51 & 2.00 & 0.53 & 5.25 & 0.007 \\
\hline Uses materials purposefully and respectfully & 2.05 & 0.49 & 2.05 & 0.72 & 2.21 & 0.60 & 4.85 & 0.010 \\
\hline Follows directions & 1.84 & 0.48 & 2.00 & 0.72 & 2.12 & 0.66 & 7.36 & 0.001 \\
\hline Uses organizational strategies & 2.07 & 0.51 & 2.09 & 0.72 & 2.14 & 0.68 & 0.38 & 0.683 \\
\hline Uses time efficiently & 1.81 & 0.55 & 1.91 & 0.68 & 2.12 & 0.63 & 8.71 & 0.001 \\
\hline Strives to produce quality work & 1.91 & 0.43 & 1.88 & 0.50 & 2.14 & 0.60 & 7.03 & 0.002 \\
\hline Completes tasks on time & 1.88 & 0.32 & 2.05 & 0.65 & 2.12 & 0.59 & 4.50 & 0.014 \\
\hline Manages transitions and changes in routine & 1.98 & 0.41 & 1.95 & 0.58 & 2.19 & 0.50 & 7.48 & 0.001 \\
\hline Exercises self-control & 1.79 & 0.56 & 1.84 & 0.69 & 1.98 & 0.71 & 3.43 & 0.037 \\
\hline Accepts responsibility for behavior & 2.00 & 0.53 & 2.00 & 0.53 & 2.12 & 0.50 & 4.51 & 0.014 \\
\hline Works quietly and stays on task & 1.79 & 0.56 & 1.74 & 0.62 & 1.93 & 0.59 & 3.97 & 0.023 \\
\hline Uses cooperation skills & 1.91 & 0.37 & 1.95 & 0.49 & 2.19 & 0.63 & 10.90 & 0.001 \\
\hline Mean score & 1.92 & 0.33 & 1.99 & 0.42 & 2.11 & 0.45 & 17.29 & 0.001 \\
\hline
\end{tabular}

student's learning outcomes may be influenced by other stressors. Students who face significant hardships outside of school or have mental challenges often struggle with school and classroom engagement.

Because school administrators recognize the importance of behavioral engagement and its linkages to academic achievement, they have sought interventions for those students who are struggling. However, well-intentioned interventions often aim to address intrapersonal and interpersonal factors of struggling students (e.g., academic, social, and personal problems) in order to address behavioral engagement (Lehr et al. 2003). As a result, these individual-level interventions may isolate a student by pulling them from their classroom or singling them out during classroom activities. It is important to note that 
Table 5 Intervention vs. control mean scores

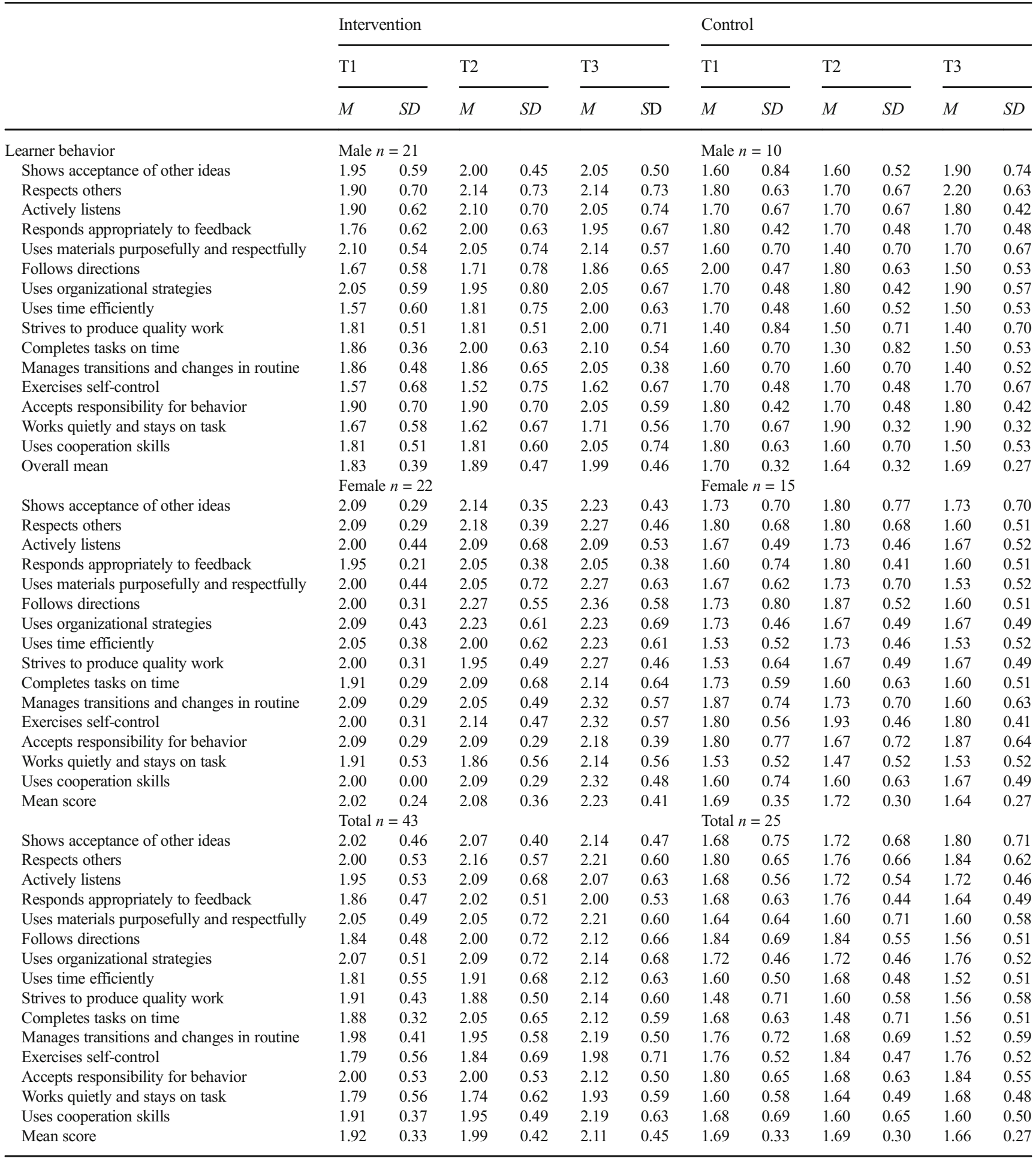

behavioral engagement, in part, includes social-emotional components related to teacher-to-student relationships (Cadima et al. 2015; Pianta and Stuhlman 2004) and student-to-student relationships (Downer 2007). Interventions that focus only on intrapersonal and interpersonal factors may therefore compromise relationships with teachers and peers that are essential to fostering social-emotional engagement and supporting positive learner behaviors.

Results of studies that have increased the amount of PA through classroom-based PA breaks have for the most part shown positive results in both behavioral engagement and academic achievement with improvements in time on task 
Fig. 1 Intervention vs. control mean learner behavior scores across time

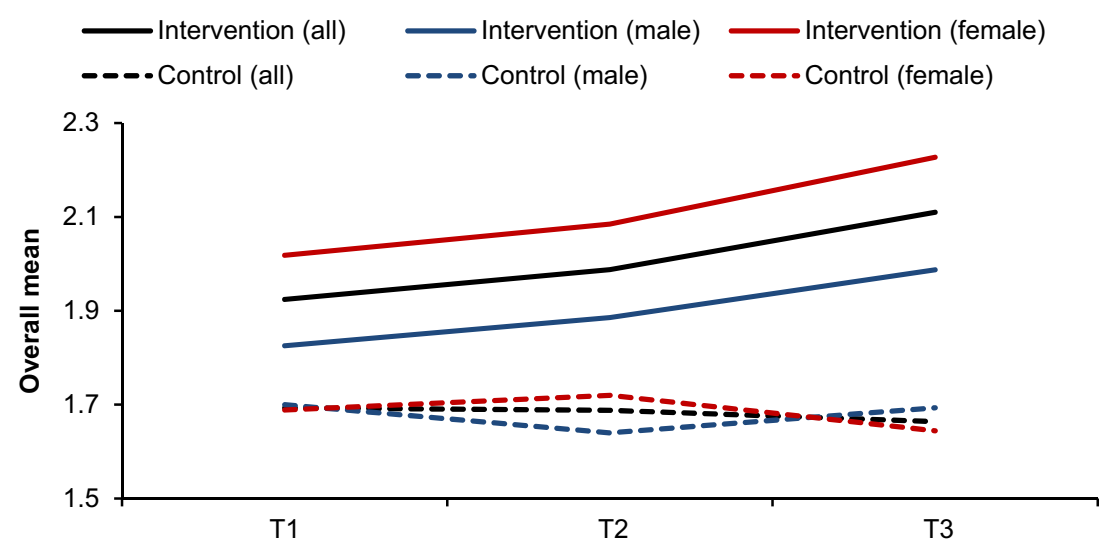

(Mahar et al. 2006), classroom behavior (Gabler-Halle et al. 1993; McKimsey and Favell 1988), attention span (McKimsey and Favell 1988), and test scores (Centers for Disease Control and Prevention 2010). Though a few studies have noted no differences between classroom-based PA and academic achievement, it is important to note that to date, no study has shown there to be any detrimental effects of classroom-based PA on behavior or academic achievement (Centers for Disease Control and Prevention 2010).

The impact that increased levels and minutes of PA can have on students who especially struggle with learning behaviors is a possible intervention that is inclusive for all students in the classroom and does not compete for instructional time. Classroom-based PA provides common ground for students to participate with each other and their teacher in an active learning environment.

The results of the present study clearly indicated that participation in classroom-based PA for students who struggle with learning behaviors enhanced several domains of behavioral engagement. Students participating in physically active academic lessons displayed significant improvements in teacher-rated classroom behaviors, while students in the traditional non-active classroom exhibited little or slight degradation in the same behaviors. It should be noted that intrapersonal skills (e.g., exercises self-control, use of time, attention to task) and social-emotional skills (e.g., acceptance of other ideas, respect for others, cooperation skills) exhibited significant improvements over the course of the year for the physically active group. Classrooms integrating PA in short increments throughout the school day provide a feasible way to engage both teachers and students and meet the requirements set forth by the Child Nutrition and Special Supplemental Nutrition Program for Women, Infants, and Children Reauthorization Act.

\section{Limitations}

There are limitations to this study, most notably in the instrument and methods used in obtaining the data. While the learning behavior instrument had been adopted from a different school district who also used the scale, to our knowledge, it has not undergone any validity or reliability testing. Secondly, the data were collected by classroom teachers and is subjective in nature and no inter-rater reliability testing was conducted. However, since the district utilizes the learning behavior scale to monitor students through their academic career, extra care is taken by teachers and counselors to ensure precision and accuracy in measuring students and identifying appropriate interventions. Third, we did not collect academic data for these students; thus, while components of behavioral engagement significantly improved in the intervention students, we do not know if this improvement also influenced academic achievement. Fourth, due to the sensitivity of the subject matter and to comply with district request, we did not collect specific information on student learning or mental disorders. Finally, because only one school district was identified in utilizing such a comprehensive measure for determining general learner outcomes among students identified with learning behavior difficulties, the sample size for this study is small.

\section{Conclusions}

Schools face a multitude of barriers today in addressing the academic challenges of students, as well as attending to physical, emotional, and mental health challenges that many students face. Of particular concern are those students who are identified with difficulties in learning behaviors. These students are at increased risk for poor academic performance despite the school administration's best efforts to address problem behaviors.

Evidence clearly indicates that moderate-to-vigorous PA can have an immense impact on not only physical health but also mental health and cognition. In accordance with the Child Nutrition and Special Supplemental Nutrition Program for WIC Reauthorization Act, all school districts must have policies in place that address PA. While schools maintain that demonstration of academic achievement is a priority, ensuring 
the health and wellness of students is also of critical importance. Though students may receive PA through physical education classes, more programs to facilitate and encourage moderate-to-vigorous PA throughout the school day must also be in place.

Combined with evidence that PA is linked to so many health and cognitive-behavioral benefits, classroom-based PA provides common ground for all students to participate without reducing time allocated for classroom instruction. Physically active lessons enhance students' behavioral engagement and, in turn, stimulate and enhance learning. Future research should further examine how physically active classroom lessons impact both learner behavior outcomes and academic achievement utilizing similar scales on students with identified behavioral engagement problems, including those students with learning and mental disorders.

Acknowledgements We thank the school district counselors in bringing this topic to our attention and allowing us to conduct the study. We also extend our thanks to the teachers, parents, and students for their willingness to participate.

\section{Compliance with Ethical Standards}

Ethics Approval and Informed Consent This study was approved by the University of Kansas Institutional Review Board, HSC \#19732. All parents provided voluntary consent for their children to participate.

Conflicts of Interest The authors declare that they have no competing interests.

Open Access This article is distributed under the terms of the Creative Commons Attribution 4.0 International License (http:// creativecommons.org/licenses/by/4.0/), which permits unrestricted use, distribution, and reproduction in any medium, provided you give appropriate credit to the original author(s) and the source, provide a link to the Creative Commons license, and indicate if changes were made.

\section{References}

Barros, R. M., Silver, E. J., \& Stein, R. E. (2009). School recess and group classroom behavior. Pediatrics, 123(2), 431-436.

Birch, S. H., \& Ladd, G. W. (1997). The teacher-child relationship and children's early school adjustment. Journal of School Psychology, 35(1), 61-79. doi:10.1016/S0022-4405(96)00029-5.

Brophy, J., \& Good, T. L. (1986). Teacher behavior and student achievement. In M. C. Wittrock (Ed.), Handbook of research on teaching (3rd ed., pp. 328-375). New York: Macmillan.

Cadima, J., Doumen, S., Verschueren, K., \& Buyse, E. (2015). Child engagement in the transition to school: contributions of self-regulation, teacher-child relationships and classroom climate. Early Child Research Quarterly, 32, 1-12. doi:10.1016/j.ecresq.2015.01.008.

Centers for Disease Control \& Prevention. (2010). The association between school based physical activity, including physical education, and academic performance. http://www.cdc.gov/healthyyouth/ health_and_academics/pdf/pa-pe_paper.pdf.
Croninger, R. G., \& Lee, V. E. (2001). Social capital and dropping out of high school: benefits to at-risk students of teachers' support and guidance. Teachers College Record, 103, 548-581.

Donnelly, J. E., \& Lambourne, K. (2011). Classroom-based physical activity, cognition, and academic achievement. Preventive Medicine (Baltimore)., 52(SUPPL), S36-S42. doi:10.1016/j. ypmed.2011.01.021.

Donnelly, J. E., Greene, J. L., Gibson, C. A., et al. (2013). Physical activity and academic achievement across the curriculum (A + PAAC): rationale and design of a 3-year, cluster-randomized trial. BMC Public Health, 13, 307. doi:10.1186/1471-2458-13-307.

Downer, J. (2007). How do classroom conditions and children's risk for school problems contribute to children's behavioral engagement in learning? School Psychology, 36(3), 413-432 http://psycnet.apa. org/psycinfo/2007-15262-006.

DuPaul, G. J., Volpe, R. J., Jitendra, A. K., Lutz, J. G., Lorah, K. S., \& Gruber, R. (2004). Elementary school students with AD/HD: predictors of academic achievement. Journal of School Psychology, 42(4), 285-301. doi:10.1016/j.jsp.2004.05.001.

Education HD of General Learner Outcome Scale. (2016). http://doe.k12. hi.us. Accessed 22 Sept 2016.

Elliot, E., Erwin, H., Hall, T., \& Heidorn, B. (2013). Comprehensive school physical activity programs: helping all students achieve 60 minutes of physical activity each day. Journal of Physical Education, Recreation \& Dance, 84(9), 9-15. doi:10.1097/ 00001610-199611000-00007.

Finn, J. D. (1989). Withdrawing from school. Review of Educational Research, 59(2), 117-142. doi:10.3102/00346543059002117.

Finn, J. D. (1993). School engagement and students at risk. Washington, DC: Natl Cent Educ Stat.

Finn, J. D. (1997). Academic success among students at risk for school failure. The Journal of Applied Psychology, 82(2), 221-234. doi:10. 1037/0021-9010.82.2.221.

Finn, J. D., Pannozzo, G. M., \& Voelkl, K. E. (1995). Disruptive and inattentive-withdrawn behavior and academic achievement among fourth graders. The Elementary School Journal, 95, 421-454.

Fredricks, J. A., Blumenfeld, P. C., \& Paris, A. H. (2004). School engagement: potential of the concept, state of the evidence. Review of Educational Research, 74(1), 59-109. doi:10.3102/ 00346543074001059.

Gabbard, C., \& Barton, J. (1979). Effects of physical activity on mathematical computation among children. The Journal of Psychology, 103, 287-288.

Gabler-Halle, D., Halle, J. W., \& Chung, Y. B. (1993). The effects of aerobic exercise on psychological and behavioral variables of individuals with developmental disabilities. (Elsevier) Research in Developmental Disabilities, 14, 359-386.

Greenwood, C., Horton, B., \& Utley, C. (2002). Academic engagement current perspectives in research and practice. School Psychology Review, 31(3), 328-349.

Hox, J. J. (1995). Applied multilevel analysis (2nd ed.). Amsterdam: TTPublikaties.

Jarrett, O. S., Maxwell, D. M., Dickerson, C., Hoge, P., Davies, G., \& Yetley, A. (1998). Impact of recess on classroom behavior: group effects and individual differences. The Journal of Educational Research, 92(2), 121-126. doi:10.1080/00220679809597584.

Kibbe, D. L., Hackett, J., Hurley, M., et al. (2011). Ten years of TAKE 10 !??: Integrating physical activity with academic concepts in elementary school classrooms. Preventive Medicine (Baltimore), 52(SUPPL), S43-S50. doi:10.1016/j.ypmed.2011.01.025.

Lehr, C. A., Hanson, A., Sinclair, M. F., \& Christenson, S. L. (2003). Moving beyond dropout prevention towards school completion: an integrative review of data-based interventions. School Psychology Review, 32, 342-364.

Levin, S., McKenzie, T. L., Hussey, J. R., Kelder, S. H., \& Lytle, L. A. (2001). Variability of physical activity during physical education 
lessons across elementary school grades. Measurement in Physical Education and Exercise Science, 5(4), 207-218. doi:10.1207/ S15327841MPEE0504 02.

Maas, C. J. M., \& Hox, J. J. (2004). Robustness issues in multilevel regression analysis. Statistica Neerlandica, 58(2), 127-137. doi: 10.1046/j.0039-0402.2003.00252.x.

Maas, C. J., \& Hox, J. (2005). Sufficient sample sizes for multilevel modeling. [References]. European Journal of Research Methods for the Behavioral and Social Sciences, 1, 86-92. doi:10.1027/ 1614-1881.1.3.86.

Mahar, M. T., Murphy, S. K., Rowe, D. A., Golden, J., Shields, A. T., \& Raedeke, T. D. (2006). Effects of a classroom-based program on physical activity and on-task behavior. Medicine and Science in Sports and Exercise, 38(12), 2086-2094. doi:10.1249/01.mss. 0000235359.16685.a3.

McKimsey, J. F., \& Favell, J. E. (1988). The effects of increased physical exercise on disruptive behavior in retarded persons. Journal of Autism and Developmental Disorders, 18, 167-179.

McNaughten, D., \& Gabbard, C. (1993). Physical exertion and immediate mental performance of 6th grade children. Perceptual and Motor Skills, 77, 1155-1159.

Naylor, P. J., Macdonald, H. M., Zebedee, J. A., Reed, K. E., \& McKay, H. A. (2006). Lessons learned from action schools! BC - an "active school" model to promote physical activity in elementary schools. Journal of Science and Medicine in Sport, 9(5), 413-423. doi:10. 1016/j.jsams.2006.06.013.

Perou, R., Bitsko, R. H., Blumberg, S. J., et al. (2013). Mental health surveillance among children-United States, 2005-2011. Morbidity and Mortality Weekly Report Surveillance for Summer, 62(2), 1-35.

Pianta, R. C., \& Stuhlman, M. W. (2004). Teacher-child relationships and children's success in the first years of school. Child Development, 33(3), 444-458. doi:10.1037/10314-000.

SAS Institute. (2002-2012). SAS/STAT 9.4 user's guide. Cary: SAS Institute Inc.

Skinner, E. A., \& Belmont, M. J. (1993). Motivation in the classroom: reciprocal effects of teacher behavior and student engagement across the school year. Journal of Education \& Psychology, 85(4), 571581. doi:10.1037/0022-0663.85.4.571.

U.S. Department of Health and Human Services. (2006). Section 204 of Public Law 108-265-June 30, 2004 Child Nutrition and WIC Reauthorization Act of 2004 SEC. 204 LOCAL WELLNESS POLICY

U.S. Department of Health and Human Services. (2008). 2008 physical activity guidelines for Americans. President's Council for Physical
Fitness and Sport Research Digest, 9(4), 1-8. doi:10.4085/10626050-44.1.5.

United States Department of Education, Institute of Education Sciences. National Center for Education Statistics CC of D (CCD). (2015). State nonfiscal surveys of public elementary and secondary education. Integrated Postsecondary Education Data System (IPEDS), Fall Enrollment Survey Spring 2001 through Spring 2014. http:// nces.ed.gov/ccd/. Accessed 1 Oct 2016.

Susan Harvey Ph.D., is an Assistant Professor of Community Health in the Department of Health, Sport, \& Exercise Sciences at the University of Kansas, Lawrence, KS.

Kate Lambourne Ph.D.

Associate

Organizational, Research, Learning and Performance

ICF International

Jerry L. Greene Ph.D.

Associate Professor

Department of Health, Sport, \& Exercise Sciences

University of Kansas

Cheryl A. Gibson Ph.D.

Professor

Internal Medicine

University of Kansas Medical Center

Jaehoon Lee Ph.D.

Assistant Professor and Associate Director

Institute for Measurement, Methodology, Analysis, and Policy

College of Education

Texas Tech University

Joseph E. Donnelly Ed.D.

Professor, Internal Medicine

University of Kansas Medical Center

Director, Energy Balance Laboratory

Director, Center for Physical Activity \& Weight Management

University of Kansas 